\section{THE PHYSICALLY HANDICAPPED CHILD}

\section{FUNCTIONAL ASSESSMENT OF THE DISABILITY AS AN AID TO PLANNING}

\author{
BY
}

E. P. QUIBELL, M.R.C.S., L.R.C.P., D.C.H. Medical Administrator, Chailey Heritage (Craft School and Hospital), Chailey, Sussex

Founded in 1903 by Dame Grace Kimmins and Miss Alice Rennie, Chailey Heritage (Craft School and Hospital) has passed through several phases in its evolution from a derelict Industrial School building, which housed the original seven crippled boys from London. These boys came under the aegis of the "Guild of the Brave Poor Things," to be trained in crafts to enable them to earn a livelihood. Vocational training of the crippled was in its infancy then, and the demand grew quickly : expansions came as money was raised by public appeals. A similar project to include training for girls soon followed: next, under the pressing influence of $\mathrm{Sir}$ Robert Jones, the need for treating the disabilities was accepted; as a result the hospital side was developed and Surgeon Commander G. Murray Levick (of Polar fame) was appointed Medical Director.

Thus a craft school and an orthopaedic hospital grew up alongside each other in lovely rural Sussex surroundings.

Finally, the spate of post-war social legislation overtook the Heritage, bringing it under the Ministry of Health in July, 1948. The school section was designated an independent special hospital school, and a separate committee of management was appointed. All children admitted, whether ambulant or bed cases, are, however, patients under the National Health Service, and therefore the final responsibility rests with the hospital authority.

Children are accepted from widely over the British Isles and the Channel Islands, and this poses considerable social problems. With increased provision in local areas for physically handicapped children planned under the 1944 Education Act, the trend has been for the more severely crippled to be referred: this stimulated new thought about the approach and led to the functional method outlined here.

\section{Nature of the Problem}

This paper refers mainly to the severe and complicated handicaps, because, with the badly disabled child, very realistic thinking is called for in order to evaluate the important defects and to plan how to tackle them. Functions of daily life and self-protection are the hard core-feeding, dressing, washing and bathing, toilet management, ambulation. Equally vital is the time factor: if the time taken in the accomplishment is excessive, it remains a serious problem in living.

In the final issue the amount of assistance needed decides the type of placement for the child : for example, the developmentally paraplegic child, with a meningomyelocele, presents difficulties of management with which few homes can cope. The laundry involved, adequate educational provision, the increasing weight of the patient, the treatment and prevention of trophic lesions, manual bladder expression, the need for bowel training and possibly regular enemataall these demand a range of knowledge and services beyond the reach of the average home, even with the most devoted parents; and it is sometimes a revelation what the parents have achieved and the ingenuity they have displayed in caring for their child.

Certain other conditions present major problems. Bilateral upper-limb poliomyelitis can cause a gross degree of handicap in daily life; and severe arthrogryphosis, extensive Still's disease, the bad athetoid form of cerebral palsy, the bilateral developmental defects of the arms, are further types.

\section{Need for a Method}

To tackle adequately the problem outlined demands a systematic approach to function : this form of evaluation highlights the important deficiencies, and upon it a coherent plan of treatment may be evolved.

Faced increasingly often with just such cases, I had felt that the anatomical analysis alone was inadequate, except in deciding the detail of operative treatment. There is even a risk that corrective surgery which at first sight appears to be anatomically sound may in fact reduce residual function still further. This was illustrated recently by a surgical colleague who had done a triceps-to-biceps transplant in a housewife to produce elbow flexion. Soon afterwards she returned highly indignant because she had lost the ability to cut a loaf of bread-evidently an important function in her life.

So much depends on what function is most valuable to the patient. This can be judged only by the test of the activities of daily life: can the hand, in fact, be used better in pronation or supination? The advantages of effective opposition of the thumb in ordinary life is rarely called into question, and tendon transplants to hold a foot in a functionally better position afford unquestioned gains.

It is mainly in the upper limb that what constitutes the most useful function is more problematical. The hand and arm have to perform so many and such varied tasks; adequate length of the arm and the ability to get it behind the trunk are necessary for cleansing after defaecation; and elevation of the limb is required for combing the hair, shaving, applying cosmetics, brushing the teeth, and endless daily jobs.

The practical test seems the only valid way for deciding the issue when advising the patient. This principle has been widely adopted in the field of industrial rehabilitation but perhaps applied too little to the problem of the disabled child; yet it leads to clearer thinking and improved planning, especially if the long-term aim of equipping the child for living and for a job is the purpose from the start.

This approach, too, can resolve such specific problems whether hand and arm function is too poor to warrant the expenditure of time and of training effort (Case 1); if so, attention can be directed to the feet. In the latter event careful thought must be given to the type of footwear, clothing, and methods of supporting clothing-elastic-sided shoes, elastic belts, zip-fasteners with big rings, coat type of shirts, and any dressing aids which are a practical help.

I believe, too, that adequate analysis of function can improve the planning of any operative surgical programme by better timing, and sometimes by even obviating doubtful and unrewarding surgery (Case 2).

In considering the badly handicapped child, one must remember that he lives (or ought to live) in a continuously expanding world, where experience and education need to keep pace with advancing years. All too often such children have lost vital years, but if operations can be timed (Case 3), so as to avoid important examination hurdles, for instance, a greater measure of progress may be preserved, provided it is without prejudice to the surgical criteria. Bone growth decides the optimal age for certain definitive surgery : even so, if the forward programme is well thought out the other needs can be woven into the pattern. Another material factor is that the aims are more precisely defined and continuity is given to the programme from all aspects. 


\section{Method}

This has two stages: (a) the actual functional analysis and documentation of the findings in considerable detail, followed by $(b)$ a full case conference of all the staff directly concerned, to evolve a planned programme for each child.

\section{Functional Analysis and Documentation}

It was decided to adopt a modification of the "proforma" used by the Bellevue Medical Center, in New York. ${ }^{1}$ This breaks down daily life functions, under certain broad headings, into considerable detail : their presence or absence is indicated by "blocking in " squares. Each function is put to a practical test. A section can be added, where applicable, to make the proforma comprehensive enough to include speech defects in cerebral palsy.

This initial documentation is done by a special staff; feeding, toilet, washing, bathing, and dressing are analysed and recorded by the nursing staff ; elevation and ambulation by the physical treatment staff ; certain hand functions, and sometimes dressing techniques, by the occupational therapist ; speech disabilities by the speech therapist. In addition, whenever possible, an intelligence test is carried out by the clinical psychologist: this is valuable as a guide to the degree of co-operation to be expected.

By this means we obtain a full and factual picture of the problem to be faced.

The Assessment Proforma.-This is lengthy; the main headings are given below, each of them being subdivided to give full details.

I. Non-walking Activities.-(a) Bed activities; (b) hygiene; (c) eating activities; $(d)$ dressing and undressing activities; $(e)$ hand activities ; $(f)$ wheel-chair activities; $(g)$ elevation activities.

II. Walking Activities.-(h) Progressing activities; (i) gait ; (j) climbing activities; $(k)$ travelling activities.

III. Summary.

IV. Recommendations. - (1) Physical Treatment: (a) physiotherapy; (b) remedial gymnastics; (c) occupational therapy. (2) Operative Treatment. (3) Speech Therapy. (4) Aids. (5) Other. (6) Educational. (7) Social Adjustment.

\section{Case Conference}

When the proforma has been completed by the staff concerned it is returned to me a day or two before the conference; this enables me to study the extent and the salient points of the disability, and helps in leading the discussion.

At the conference, the report is considered by all the staff directly concerned-medical, nursing, physiotherapy, remedial gymnast, occupational therapist. The almoner attends, as direct social problems are so often involved. The psychiatrist, clinical psychologist, and speech therapist are invited to participate whenever their special help is needed. The teaching staff also participates, and their presence proves very valuable. The details of the proforma are discussed section by section, and the possibilities weighed up ; opinions are freely invited and decisions made on both the way and the person to tackle the particular function in question.

At this stage the child attends so that his or her own opinion can be sounded and any particular problem studied-for example, whether writing is better done by mouth than by hand.

The above procedure gives the staff a clear picture of the extent of the disability and provides as wide a context as possible for considering the child's future programme; further, it helps to eliminate overlapping and waste of time. It may bring to light psychological factors adversely affecting the child's morale and co-operation (Case 4). Expert advice can then be sought from the psychiatrist.

My secretary sits in at the conference to keep notes of the proposals put forward and conclusions reached. These are typed and distributed to the staff involved in the rehabilitation programme, which defines clearly what is delegated to each participant.

A system of periodical progress reviews is being planned : with larger experience this will yield much valuable knowledge of the results and the time taken to achieve them. Already certain features stand out as vital. Under the hygiene section, the question of toilet management requires very careful analysis; in employment it may be a deciding factor, and undoubtedly it drastically increases the person's self-respect. Even a quite young child resents being dependent on others for such help. The time factor in dressing and putting on appliances can be a serious hindrance; careful thought and practice given to the method of doing these can be rewarding. For example, it may be better for a child to put on his footwear and callipers before a spinal support, otherwise he may find it impossible. These are elementary points, but frequently they are overlooked and much time is wasted. A practical try-out can soon settle the doubt.

As our team's experience grows, the advice can become more precise and be given earlier. Simple modifications of clothing which really economize time and effort can be settled at the start: there is here real value in having a mixed team.

\section{Value of the Method}

Even in the limited period of its operation the value of the approach has seemed clear, and the staff have found it instructive, stimulating, and, on occasion, starkly revealing of how severe these handicaps can be in daily life. It has evoked really hard thinking with regard to ways and means of overcoming these handicaps. Sometimes the difficulties prove baffling. Equally, the conference allows a much greater pooling of ideas and suggestions: this has been especially so in matters of clothing adjustments, aids, and functional training. It avoids the predicament of discovering a serious social limitation at the last moment, when employment is looming up and no time is left to tackle it.

Where a psychological attitude impedes co-operation the psychiatrist can advise and the whole team then work in concert to overcome it. This can sometimes be the key to success; a severe attack of poliomyelitis coming in early teenage can have a devastating impact, and it needs very good team-work, in an atmosphere of guarded optimism and confidence, to tide over the worst phase. This we have seen more than once.

The team involved may appear large and the method extravagant of time. So far this has not been borne outif anything, rather the reverse : by having the complete picture presented to all simultaneously it has reduced crossreference of difficulties. The seriously disabled child calls on many services-medical, nursing, physical treatment, educational, social, psychological ; therefore the closer the integration of the team-work the better the results.

As experience grows we find each case can be considered more expeditiously and quicker solutions reached. The question of medical responsibility may be raised against the method. I do not think this responsibility is affected: the surgeon decides what surgery should be done, and when; and the plan is worked out by agreement. Medically, I think we have moved into the era of team-work, and frank discussion can extend one's knowledge usefully: thus in the long run one may become a wiser and more considerate counsellor.

Finally, the courage and optimism of such disabled children give a spur-if such is wanted-to our ingenuity, and act as a reminder of our own good fortune in having whole limbs. "Over and over again this courage has enabled them to do the seemingly impossible." 2

\section{Illustrative Cases}

Case 1.-Girl aged 6 years 11 months; average intelligence, I.Q. $100+$. Disability: poliomyelitis, upper limbs ; left arm flail ; right arm, limited hand function only. Socially very 
handicapped : can perform a number of play activities-for example, dressing dolls-with her feet. Cannot adjust clothing for toilet ; can feed herself a little, using a spoon or fingers; needs almost all dressing done; is afraid of stairs (had a fall at home and fractured her left humerus) as she cannot protect herself. The problem posed was whether hand function would be adequate to gain much independence, or whether she should be trained to use her feet. The case conference showed that training could achieve much regarding toilet; modifications to clothing could help materially with dressing; training, and the building of confidence, could overcome the fear of stairs. Operative treatment would improve thumb opposition, and hence hand function. It was agreed that the hand was sufficiently good for every effort to be made to improve its use and not to turn entirely to feet training.

Case 2.-Girl aged 15 years 9 months; I.Q. 87. Disability: arthrogryphosis multiplex congenita, all limbs; minimal power in both arms and both legs. Between May, 1942, and May, 1954, this girl had 13 orthopaedic operations-six on the arms and seven on the legs-also 10 manipulations under general anaesthesia, with plaster-ofParis splints; at various hospitals. At the end of this formidable programme she remains grossly handicapped: virtually everything has to be done for her-feeding (mainly), dressing, toilet, washing, and bathing (completely). She can roll from side to side in bed; she can write with her mouth, and drink by holding a cup in her teeth or using a straw; she can walk with callipers and surgical boots (when they are put on for her) on the level and up a slight incline going sideways. She cannot protect herself if she falls. It seems possible that some of the surgery may have had an adverse effect ; certainly much of it failed in its purpose. The case conference clearly exposed the serious degree of social handicap, and showed that residential placement was the only solution in view of family difficulties. It was decided that work, using her mouth, should be found to give her an interest and a sense of usefulness. Had the functional method of assessment been applied at an earlier stage the amount of operative and manipulative treatment might well have been reduced. As she cannot manipulate knee locks on the callipers, sitting is very awkward: she has to either stand or lie. She requires a special chair with foot-rests ; this is being evolved.

Case 3.-Boy aged 11 years 4 months; I.Q. 165 . Disability: poliomyelitis, upper limbs; right arm flail; left arm, very limited function. A highly intelligent boy who has taught himself many trick methods: limited over toilet, cutting up food, and parts of dressing and washing. Lefthand function could be improved by surgery. Should go for academic career; educational needs are therefore very pertinent. The case conference revealed that simple modifications of clothing would assist with toilet management ; special toothbrush and long sponge needed; tests for feeding aids were required. Operation should be undertaken early to allow time for working for G.C.E. ; date settled. These were the main immediate agreed points; each was allocated to the appropriate person-for example, occupational therapist to evaluate feeding aids, assistant matron to arrange clothing alterations with sewing-room staff.

Case 4.-Boy aged 14 years 4 months; I.Q. 111. Disability : poliomyelitis, upper limbs ; right arm flail ; left arm very poor. Late onset of poliomyelitis at age of 12. Always keen to take up farm work. Average intelligence, deeply resentful of his disability. Is heavily handicapped, requiring help with toilet, feeding, dressing, washing, bathing; has to use his mouth in writing. Social conditions difficult: mother deserted family; father lives in lodgings, but is concerned for boy's welfare, financial position difficult. The case conference emphasized the serious degree of handicap: the psychological attitude required expert advice by the psychiatrist. Surgery could improve the function of the left hand, and should be started at once, as time is short; even then he should be trained to get the maximum use of his feet. The home conditions need careful investigation and stabilization, so that simple home aids can be used. Employment will require hard thought. Modified footwear is desirable.

\section{Conclusions}

Proper evaluation of this approach to functional disability needs prolonged and careful study by a team who can watch and review the children over the full period of training and treatment.

The method can anticipate forward problems, thus allowing time for better advance planning.

It provides a forum at which experience and advice can be pooled and the overall needs of the child considered.

The approach is factual and systematic ; it presents a complete picture and provides a method of checking progress.

Social difficulties are more clearly foreseen; hence the almoner can start early investigations and discussion with the family and authorities.

When the scheme has been longer in operation it should yield a useful pool of experience with wider applications.

The method is designed to deal with the more complicated and severe handicaps in children.

It improves team-work, yet need not conflict with medical responsibility.

I would like to thank the many members of the Heritage staff who are co-operating so helpfully in the scheme.

\section{REFERENCES}

1 Bellevue Medical Center, Institute of Physical Medicine and Rehabilitation, 400, East 34th Street, New York, 16, N.Y., U.S.A.

Disabilities and How to Live with Them (1952). Foreword. Lancet Ltd., London.

\section{CHALLENGE OF MONGOLISM}

A meeting on "Current Research in Mongolism" was held on October 3, with Dr. L. T. Hilliard in the chair, at the Fountain Hospital. Professor L. S. PENRose, F.R.S., of the Galton Laboratory, began by describing mongolism as a challenge. It was a specific disorder and a common one, yet little was known about its causation. Many theories had been put forward, but they had little value without new data. Attempts must be made to find new data even though the results would often be negative. For example, the antigenic relationships between mother and child had been studied, but any deviation from expectation was in the direction of resemblance, not dissimilarity.

Studies on twins were difficult to interpret. One or two examples of concordant pairs of dizygous twins were now known, but no proved example of a discordant monozygous pair. Family studies showed only a low incidence of mongolism in the sibs of mongols ; there was perhaps a two- or three-fold increase in the risk to sibs. The effect of maternal age was well known, but there was little evidence that maternal ill-health predisposed to mongolism. A maternal cytoplasmic factor'was a possibility. He had therefore been interested in a pair of monozygous twin mothers in Dr. Carter's survey, who had each had a mongol child within a few years of each other. But he had also heard of an instance where it was the fathers who were monozygous twins.

\section{Heredity and Environment}

Dr. C. O. CARTER described some results of a survey of over 550 mongols on which he had been engaged with Mrs. K. Evans at the Hospital for Sick Children, Great Ormond 